\title{
A Method Exploration of Combining the English Education with the Professional Course of Science and Engineering
}

\author{
Xing-Ji ZHU ${ }^{1, a}$, Zhao-Zheng MENG ${ }^{1, b}$, Mei-Ping $\mathrm{HE}^{2, \mathrm{c},{ }^{*}}$ and Ying-Zi ZHANG ${ }^{1, \mathrm{~d}}$ \\ ${ }^{1}$ Department of Civil Engineering, Harbin Institute of Technology at Weihai, Cultural West Road, \\ Weihai , 264209, PR China \\ ${ }^{2}$ School of Languages and Literature, Harbin Institute of Technology at Weihai, Cultural West Road, \\ Weihai, 264209, PR China \\ azhuxingji@hit.edu.cn, b161210228@stu.hit.edu.cn, chemeiping@hit.edu.cn, ${ }^{\mathrm{d}}$ zhyz@hit.edu.cn \\ ${ }^{*}$ Corresponding author
}

Keywords: English, Education, Science and engineering, Professional courses.

\begin{abstract}
With the deepening of globalization and more frequent international communications, English education has been attached to great importance. Therefore, students majoring in science and technology should also focus on specialized English study to improve their global horizon. The excellent professional English skills can make them more competitive and attractive in the employment market. This paper proposes a new innovative method for the education of specialized English which is combined with the professional courses of science and engineering. It can maximally arouse the passion and initiative of students for studying the specialized English, while ensuring the quality of education for the professional course.
\end{abstract}

\section{Introduction}

The development of human society relies deeply on the exploration of science and technology. Given the inclination that international cooperation is gradually common in academic researches, internationalization is increasingly significant in the majors of science and engineering [1,2]. Especially with the deepening development of "one Belt and one Road" strategy, more domestic companies go abroad. Meanwhile, more students majored in science, technology or engineering choose to study abroad and participate in oversea scientific research institution. Those all put forward higher standards of specialized English for the students.

However, there are distinct differences in specialized English teaching methods and results among Chinese colleges and universities. How to inspire the enthusiasm of autonomously studying specialized English is the key factor to influence the teaching effect. This paper compares two main educating methods in Chinese universities nowadays, and proposes an innovative teaching method. The newly developed method combines the guidance and practice. Its main aim is to improve the specialized English level of students significantly.

\section{Analysis of the Current Situation for Specialized English Teaching in Science and Technology}

At present, the education of specialized English for the science and engineering students mainly includes two approaches: (1) full English teaching in the professional course, and (2) setting up specialized English courses independently. These two method is adopted wildly in almost all Chinese universities.

As for the full English teaching method, there is no doubt that it will contribute to the specialized English level of students, but it cannot be denied that students have difficulties in understanding the professional knowledge. Under the situation that not all university students can comprehend the contents mentioned in full English teaching class, it is not realistic to apply this method in the specialized English education. In addition, usually there are lager differences for the ability of English 
language among teachers from different universities[1,2]. Numerous teachers cannot guarantee the quality of the specialized English education. Some schools may even cannot implement this teaching method effectively. And in nowadays' education system, most of students tend to pay more attention to CET4 and CET6 test rather than specialized English learning [1].

As for the method that sets up specialized English courses independently, it can not only ensure the teaching quality of knowledge but also make the teaching plan flexible. For example, teacher can design courses aimed at the key points and difficulties in the specialized English study. It will also not be affected by professional knowledge. However, this method may lead to low enthusiasm of students, and little importance is attached to English study [1]. Consequently, the teaching effect is not remarkable in practice. It is noted that the aversion to English study also remains stable among students [3].

In conclusion, it is obvious that these two methods mentioned above always catch one and lose another. They always fall into a dilemma that choosing the lesser of two evils is inevitable. Hence, an innovative method that combines the specialized English with professional courses together is necessary for specialized English education.

\section{An Exploration of Introducing the English Education into the Professional Course}

\section{Basic Idea of the Innovative Teaching Method}

Firstly, we analyze the English learning characters of students of science and engineering. English, as a liberal arts course, has significant differences with science and engineering courses, especially in learning method. Students of science and engineering prefer learning by comprehension, memorization and exercise. Their thinking is relatively intuitive. However, the learning method of English, except including gammas and words memorization, focuses more on the improvement of humanistic literacy which is the drawback of students of science and engineering. Therefore, improving in practice, application and combination with professional courses is the better teaching method.

Plus, we propose a performance-guiding teaching method, which means that the grade in specialized English is a composition of grades in professional courses. In this method, we can inspire the learning motivation of students and make students pay more attention to specialized English study. The main assessing method nowadays is that ordinary performance accounts for $20 \%$, and final exam accounts for $80 \%$ of the total score. However, this mainstream assessment is so inflexible and boring that cannot arouse the studying enthusiasm of the students [4,5]. Besides, there is only the input of knowledge including teaching translation and reading skills, while the practice are lacking[6].

In the end, the studying process of a second language cannot make progress without the help of mother language. Therefore, teaching with Chinese and English is adopted to help students understand the knowledge better.

\section{Specific Implement Methods}

First, using Chinese in professional courses, with introduction of specialized vocabulary and background knowledge in English, is applied in this method. For example, when teaching the knowledge of Portland cement, we can introduce the English name of cement and the invention of cement. It can not only arouse the motivation but also help students get a good command in specialized English vocabularies.

Second, given the heavy course load on students of science and engineering, we choose to use English to explain exercises and assignments. In this way, students are not under too much pressure and can also acquire knowledge in specialized English.

Last but not the least, to relate the specialized English level to professional course grades, the quizzes and mid-term examination are all in English version. We also examine the specialized vocabulary, specialized translation and specialized reading comprehension, etc. In addition, it can 
also provide more opportunities for students to output the knowledge about specialized English. Students can improve English level in practice.

\section{Actual Sample Investigation and Research}

\section{Sample for the Investigation}

The information about sample and contrast sample is listed below.

(1) Grade of sample: 2015; Size of sample: 153;

Major of sample: Civil engineering;

Testing course: Design Theory for Concrete Structure (I).

(2) Grade of contrast sample: 2016; Size of contrast sample: 110;

Major of contrast sample: Civil engineering;

Testing course: Design Theory for Concrete Structure (I).

To illustrate the achievements of the newly proposed method, we compare the test results of grade 2016 and grade 2015 respectively. Students who attend the examination major in civil engineering. It is in grade 2015 that we carry out the innovative specialized English teaching method.

\section{Examples of the Test Question}

\section{Words Exercise}

In this section, you are supposed to write the Chinese meaning of each English word or phrase.

Concrete, 2) Portland cement , 3) reinforcement , 4) strain, 5) elasticity modulus , 6) rigid body , 7) displacement, 8) pore structures , 9) beam , 10) boundary condition

\section{Translation}

In this section, you are supposed to translate the English sentences into Chinese.

1) The corrosion of steel reinforcements is a significant durability problem causing damage to reinforced concrete structures

2) A number of simulations of the carbonation process are found in the literature

3) The binding capacity of concrete must also be influenced by carbonation.

\section{Reading Comprehension}

In this section, you are supposed to read a part selected from an essay, and then answer the questions below

The carbonation of concrete is a complex physical and chemical process. In our model, this process is divided into four parts: transport of carbon dioxide, mass balance of dissolved calcium hydroxide, dissolution of solid calcium hydroxide into concrete pore solution, and chemical reaction of CSH with carbon dioxide

When carbonation occurs, the pore structure and material properties of concrete will also change. This will seriously affect the transport of moisture, chloride ions and carbon dioxide. Therefore, establishing a mathematical model which can reflect the variations of concrete pore structure in different degrees of carbonation is important.

1) What kind of material in the concrete will react with carbon dioxide according to the passage and the knowledge you learn in class?

2) What are the effects of carbonation according to the second paragraph?

3) What may be discussed in the following part of this essay?

\section{Analysis and Explanation for the Test}

The vocabulary part aims to examine the comprehension and memorization of specialized English words. Words that have special meaning in science and engineering field are the difficulties for students learners[4], and these words are mainly focused. For example, the commonest meaning of 
strain is stress and tension, while it means deformation of a physical body in civil engineering area. In addition, the academic words which may be used in searching literature are examined.

The translation part aims to test the comprehensive ability to sentences and understanding of professional knowledge. Understanding sentences which include specialized vocabulary is a necessary skill in reading specialized papers.

The reading comprehension part aims to examine the integrated ability in specialized English. It requires students to combine the specialized English knowledge with professional knowledge to answer comprehensive questions. In this process, students can gain a sense of achievement and be more enthusiastic to learn specialized English.

\section{Results Discussion}

To examine our teaching results, we compare excellent rate, pass rate and average scores of students who take the innovative specialized English education and those not, as show in Fig.1. Although they take the same test, the test results have significant differences. We regard 85 as the excellent line of this test. In addition, we analyze the score distribution of students who have the innovative specialized English education. An investigation concerning the rate of students who read English literature actively is also conducted.

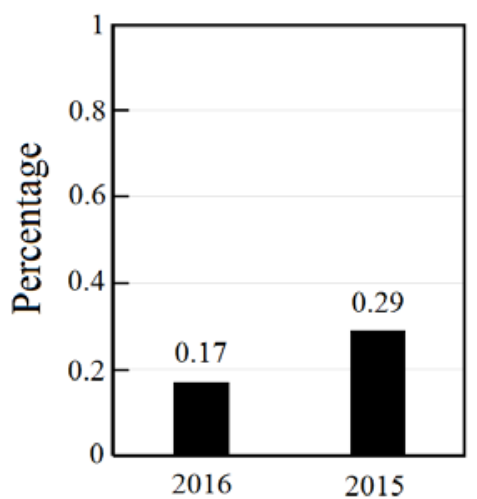

(a)

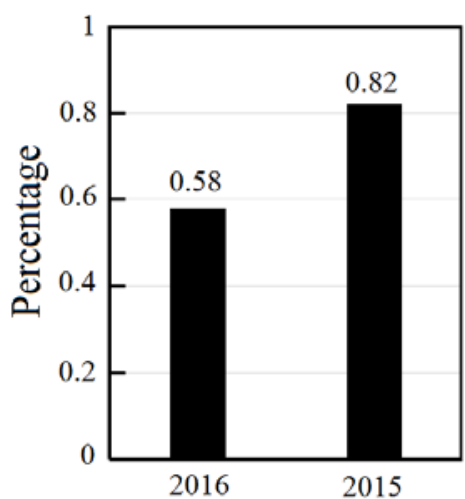

(b)

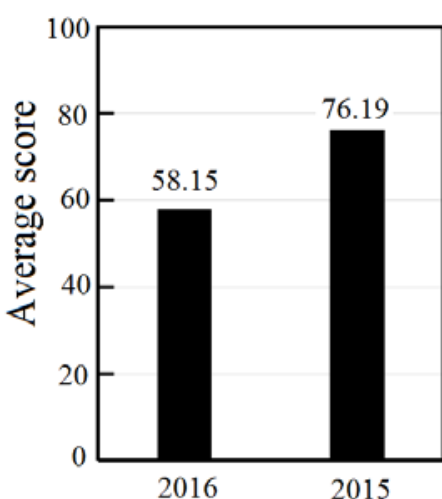

(c)

Figure.1 Comparison of the test results between with and without our innovative English education for (a) excellent rate, (b) pass rate, and (c) average scores.

The bar charts above compare the excellent rate, pass rate and average scores of students in grade 2016 and grade 2015, respectively. It is obvious in these graphs that excellent rate and pass rate of grade 2015 are significantly higher than those of grade 2016. Under the assumption that the initial English levels of both grades are the same, the exceeding part of the excellent rate in grade 2015 represents the achievements of our teaching method. By comparing the average scores of two grades, we discover that the average English level of grade 2015 has increased remarkably.

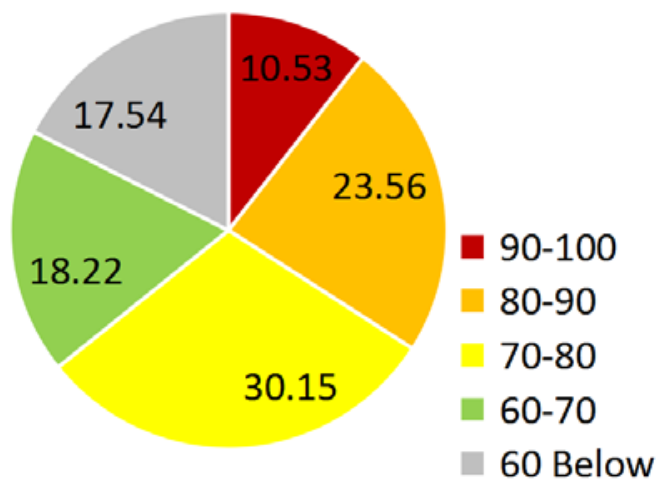

Figure.2 Proportion of each score segment in grade 2015. 


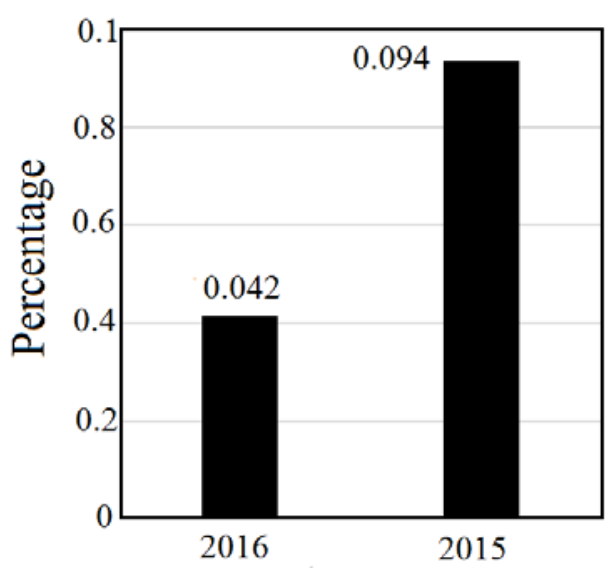

Figure.3 Statistical results of the number of students who read English papers actively.

Fig.2 demonstrates the proportion of each score segment in grade 2015. Judging from the pie chart, we can discover that students who scored between 70 to 80 takes part more than 50\%. However, there are still some students get more than 90 points.

Meanwhile, we conduct an investigation which aims to get effective suggestions and feedback about specialized English study. We also investigate the number of people who read English papers actively. The statistical results are given in Fig.3. We calculate the percentage of those people in the total sample size. As shown in bar chart below, the number of students who read English references actively in grade 2015 is higher than that in grade 2016, which is identical with our expectation. Therefore, by comparison, it is obvious that our teaching method is effective.

\section{Summary}

With the frequent international cooperation, specialized English education is attached to increasingly more importance. Based on the mainstream teaching method nowadays, we explore the new method to introduce specialized English into science and engineering courses. Meanwhile, we analyze the advantages and disadvantages of past teaching method, combine features of English study of students in science and engineering, emphasize the importance of practice and try to absorb the essence and discard the dregs. Improving in practice is the core idea of our teaching method.

By analyzing data, we find the innovative teaching method can improve the specialized English level and inspire the enthusiasm of English study. This is also in line with the goal of building the world-class university.

\section{Acknowledgement}

This research was financially supported by the National Natural Science Foundation of China (51308166). Xingji Zhu also appreciates the support of Major Program of Mutual Foundation of Weihai City with Harbin Institute of Technology (Weihai).

\section{References}

[1] Q.U. Li-na, Y. Zhai, Understanding and Reflection on the Professional English Teaching for Science and Engineering Majors, Journal of Huaihai Institute of Technology. 13 (2015) 123-126.

[2] L. Zhang, L. Liu, The Discussion on Teaching Methods of Subject Based English(SBE) in Engineering Universities and Colleges, Science and Technology of West China. 03 (2009) 81-83.

[3] C.L. Li, Study on Demotivation of English Learning among Non-English Major Students of Sciences and Engineering: A Perspective of Dynamic System Theory, Journal of Huaihai Institute of Technology. 15 (2017) 136-140. 
[4] J. Li, Y. Zhang, M. Zhang, R.L. Zhang, Specialized English examination reform of civil engineering, Journal of Architectural Education in Institutions of Higher Learning. 01 (2016) 114-116.

[5] F. Wang, X.R. Dong, The Discussion on Teaching Methods of ESP in Engineering Universities and Colleges, Journal of NUC(Social Sciences). 02 (2005) 63-65.

[6] X.R. Zhu, Discussion on the Teaching Methods of Professional English for Science and Engineering Majors, Journal of Jiangsu Polytechnic University. 02 (2006) 72-74. 